Article

\title{
Simulation of Land-Use Changes Using the Partitioned ANN-CA Model and Considering the Influence of Land-Use Change Frequency
}

\author{
Quanli Xu ${ }^{1,2,3,4, *}$, Qing Wang ${ }^{1,2,3,4}$, Jing Liu ${ }^{1,2,3,4}$ and Hong Liang ${ }^{1,2,3,4}$ \\ 1 Department of Geography, Yunnan Normal University, Kunming 650500, China; \\ manhaoluo@gmail.com (Q.W.); matajing0715@gmail.com (J.L.); 4077@ynnu.edu.cn (H.L.) \\ 2 GIS Technology Engineering Research Centre for West-China Resources and Environment of \\ Educational Ministry, Kunming 650500, China \\ 3 Yunnan Geospatial Information Technology Engineering Research Center, Kunming 650500, China \\ 4 Key Laboratory of Resources and Environment Remote Sensing, Yunnan University, Kunming 650500, China \\ * Correspondence: xql_ld@ynnu.edu.cn; Tel.: +86-0871-6594-1255
}

\section{check for}

updates

Citation: Xu, Q.; Wang, Q.; Liu, J.; Liang, H. Simulation of Land-Use Changes Using the Partitioned ANN-CA Model and Considering the Influence of Land-Use Change Frequency. ISPRS Int. J. Geo-Inf. 2021, 10, 346. https://doi.org/10.3390/ ijgi10050346

Academic Editors: Costantino

Domenica, Massimiliano Pepe and Wolfgang Kainz

Received: 22 March 2021

Accepted: 15 May 2021

Published: 18 May 2021

Publisher's Note: MDPI stays neutral with regard to jurisdictional claims in published maps and institutional affiliations.

Copyright: (c) 2021 by the authors. Licensee MDPI, Basel, Switzerland. This article is an open access article distributed under the terms and conditions of the Creative Commons Attribution (CC BY) license (https:// creativecommons.org/licenses/by/ $4.0 /)$.

\begin{abstract}
Land-use change is a typical geographic evolutionary process characterized by spatial heterogeneity. As such, the driving factors, conversion rules, and rate of change vary for different regions around the world. However, most cellular automata (CA) models use the same transition rules for all cells in the model space when simulating land-use change. Thus, spatial heterogeneity change is ignored in the model, which means that these models are prone to over- or under simulation, resulting in a large deviation from reality. An effective means of accounting for the influence of spatial heterogeneity on the quality of the CA model is to establish a partitioned model based on cellular space partitioning. This study established a partitioned, dual-constrained CA model using the area-weighted frequency of land-use change (AWFLUC) to capture its spatial heterogeneity. This model was used to simulate the land-use evolution of the Dianchi Lake watershed. First, the CA space was divided into subzones using a dual-constrained spatial clustering method. Second, an artificial neural network (ANN) was used to automatically acquire conversion rules to construct an ANN-CA model of land-use change. Finally, land-use changes were simulated using the ANN-CA model based on data from 2006 to 2016, and model reliability was validated. The experimental results showed that compared with the non-partitioned CA model, the partitioned counterpart was able to improve the accuracy of land-use change simulation significantly. Furthermore, AWFLUC is an important indicator of the spatial heterogeneity of land-use change. The shapes of the division spaces were more similar to reality and the simulation accuracy was higher when AWFLUC was considered as a land-use change characteristic.
\end{abstract}

Keywords: dual-constrained spatial partition; ANN; partitioned CA; land-use dynamic simulation; Dianchi Lake watershed

\section{Introduction}

Land-use and land-cover change (LUCC) are very important processes and represent the most direct outcome of the interaction between humans and landscapes. Not only is LUCC an important factor affecting the global ecological environment and climate change, but it also plays a critical role in areas such as sustainable regional development and urban planning [1]. Therefore, understanding the evolution of LUCC and its patterns may help elucidate the mechanisms underpinning human-land interactions and may reduce the human-land conflict and promote sustainable regional development [2]. LUCC is a dynamic process driven by the integration of natural and anthropogenic landscapes, and its formation mechanism is extremely complex. As such, it is often necessary to use landuse simulation models to understand the evolution of land-use change and its results [3]. Cellular automata (CA) is a "bottom-up" dynamic model that is discrete regarding time 
and space. It is able to simulate the spatio-temporal evolution of complex systems and is an easy model to understand and program. In recent decades, this model has been extensively used by researchers in land-use evolution and urban expansion studies [4-6]. The conversion rule is a transformation function that specifies how a cell is able to change its state from one moment to the next. The conversion rule is the dynamic basis of CA to simulate the evolution of a complex system; it has an important influence on the simulation process and results $[7,8]$.

There are many conversion-rule mining methods for the CA model. In a realistic application, it is necessary to select an appropriate method to determine cellular conversion rules based on the object of the simulation. Commonly used conversion-rule mining methods may be classified into three categories: logistic regression (LR), Markov chain (MC), and artificial intelligence (AI). The LR model uses the logistic function to construct the relationship between land-use type (dependent variable) and its driving factors (independent variables). It normalizes the value of the dependent variable to zero or one to calculate the land-use type conversion probability $[9,10]$. The LR model is an effective method for mining the CA conversion rules; however, as it is essentially a linear-fitting method, it is difficult to express the non-linear characteristics of land-use change. Therefore, the conversion rules constructed using this method are usually inaccurate. The MC model maps land-use types to states, and the next time point is dependent on the transition probability between the current state and the next one. The land-use state transition probability at adjacent moments is considered the key to constructing a transition rule using a Markov chain model. Typically, the land-use-type transition matrix of the two-phase land-use change is used to determine the state transition probability between land-use types at consecutive points in time [11]. An MC model is able to generate the transfer probability matrix of land-use change based on the transfer direction and quantity between land-use types; these are effective for mining land-use change conversion rules. However, this model is unable to characterize the impact of the driving forces on the process of land-use change. As such, it is often necessary to combine other methods to improve the accuracy of conversion rules. AI refers to a series of methods that use computers to complete specific intelligent activities. This is an idea or framework that uses computers to build automated analysis tools or models that are partially similar to human intelligence to help solve complex problems. Compared with the LR and MC models, this "human-like intelligence" characteristic of AI methods is relatively easier for discovering knowledge and calculating and expressing complex relationships, for example: dealing with non-linearity and uncertainty in land-use change, which improves the accuracy of the CA model conversion rules. Currently, the AI methods used to mine the CA conversion rule mainly includes a tree-based decision [12], support vector machine (SVM) [13,14], ant colony algorithm (ACO) [15,16], genetic algorithm (GA) [17], and neural network (NN) [18]. Many researchers conducted a comparative analysis of the effects of these algorithms in the mining of CA model conversion rules. This was carried out to optimize the automatic mining method of CA conversion rules based on AI algorithms [19-24]. Their results showed that the ANN was better able to analyze non-linear complex phenomena and avoid the automatic acquisition of conversion rules during intermediate calculations. Its self-organization, self-learning, association, and memory were effectively able to simplify the acquisition of CA model conversion rules, extract CA conversion rules from the original training data, and avoid subjective factors, thus improving simulation accuracy. Thus, the NN is an efficient scientific method for mining CA model conversion rules.

However, the accuracy of the CA model is affected by the accuracy of the conversion rule and the scale of conversion-rule mining. For conversion rules, this has a significant spatial scale effect [25] on the impact of the driving factors of land-use change and their spatial distribution patterns and may be measured from two aspects: spatial dependence and spatial heterogeneity. Spatial dependence describes the extent to which the state of a cell is affected by the state of the surrounding cells. This means it measures the effects of spatial interaction between land-use types and land-use changes and driving factors [26]. 
As the CA model itself has significant neighborhood characteristics, the spatial interaction of the cellular transformation rules is generally expressed by defining the shape and size of the cellular neighborhood. This eliminates or weakens the spatial dependence effect of the cellular transformation rules [27].

Spatial heterogeneity is another important theory for explaining the laws of geographic distribution. It describes the phenomenon by which the attribute values of a spatial unit changes, with modifications to the spatial unit as a result of geographic isolation [28]. Land-use change is a typical geographic evolutionary process characterized by spatial heterogeneity. However, most current CA models use unified land conversion rules to simulate land-use change, dismissing the influence of the spatial heterogeneity of land-use change on the model. As such, the model is prone to over- or under-simulation, which means the simulation results substantially deviate from reality [29]. An effective means to accommodate the influence of geographic heterogeneity on the quality of the CA model is to establish a cellular space partition mechanism. This involves dividing the cellular space according to the spatial heterogeneity characteristics of land-use change; each partition inside the cell then has more similar attributes in characterizing land-use change. As such, the conversion rules of each partition are able to express the driving mechanism of land-use change in the area more accurately, thereby improving the accuracy of the CA model simulation [30]. There are two main methods for cellular space partitioning: one, based on an administrative area and the other on dual-constrained space clustering. For example, Yang et al. [31] used sub-administrative divisions to classify research into several sub-areas. They used LR analysis to construct the land-use evolution parameters and conversion rules of these sub-areas, and then constructed a division of the urban expansion CA model for Dongguan. The results showed the improved simulation accuracy of the partitioned CA model. The main disadvantage of dividing the cellular space by administrative districts is that the divisions are highly subjective, and it is difficult for them to express the similarity of land-use change characteristics. Ke et al. [29,30,32] proposed a dual-constrained spatial clustering method to partition the cellular space. They sought to comprehensively consider the similarity in the spatial and attribute relations of land-use change; as such, a clustering method was used to realize the partitioning of the cellular space. Although some studies showed that the dual-constrained spatial clustering partition method was more objective than administrative district partitioning, there were problems, such as the single-constraint attribute and difficulties reflecting the key characteristics of land-use change.

In summary, the mining method for cellular conversion rules has evolved from linear methods (e.g., statistics) to AI methods such as NNs. Many research results show that NNs are scientific methods to mine cellular conversion rules, thereby improving the simulation accuracy of land-use change. Partitioning cellular space based on the similarity of landuse change features and constructing a partitioned CA model is an effective means for eliminating or weakening the influence of spatial heterogeneity. However, determining the similar attributes that better characterize land-use change is still a problem requiring in-depth research. The frequency of land-use change (FLUC) refers to the number of times a land-use type has changed within a certain period (e.g., year or month). FLUC is a key indicator of the spatio-temporal evolution of land use. It is able to consider the frequency and amplitude of land-use transformation among land-use types and express its intensity in the region [33]. Therefore, the addition of the FLUC to the attribution collection to measure the similarity of change may provide insight into the spatial heterogeneity of the processes and causes underpinning it more accurately.

Based on this research, this study applied the FLUC as the key attribute for understanding the process of change in the Dianchi Lake watershed. This was carried out using the partition method with dual-constraint criterion and the NN method. A simulation model of partitioned CA was established to improve model quality. First, a clustering method with dual-constraint criteria (spatial and non-spatial features) was used to detect the geographic heterogeneity of change; this formed the basis of cellular space partitioning. Second, an ANN model was used to mine the unified and partitioned cellular conversion 
rules. Then, the two CA models of the partitioned and unified rules were compared and analyzed to verify the effectiveness of the partitioned CA model. Based on the verified model and the simulation results, this research may serve as a decision-making basis for planning and spatial layout optimization in the Dianchi Lake watershed.

\section{Materials and Methods}

\subsection{Study Area}

The Dianchi Lake watershed is located in the central Yunnan-Guizhou Plateau $\left(24^{\circ} 28^{\prime}-25^{\circ} 27^{\prime} \mathrm{N} ; 102^{\circ} 29^{\prime}-103^{\circ} 0^{\prime} \mathrm{E}\right)$, covering an area of approximately $3000 \mathrm{~km}^{2}$. In this watershed, the Dianchi Lake to the southwest is the sixth largest freshwater lake in China. The altitude of the study area is between 1860 and $2809 \mathrm{~m}$ above sea level, and, in general, the terrain is high in the north and low in the south. As such, the topography is characterized by a long, narrow intermontane basin from south to north. The climate in the watershed is warm and moist with distinct wet and dry seasons. The annual average temperature is $15^{\circ} \mathrm{C}$; average annual sunshine is more than $2200 \mathrm{~h}$; and average annual precipitation is approximately $1050 \mathrm{~mm}$. The area also contains many different vegetation types with high vegetation coverage such as arbores (Populus Yunnanensis, Taxodiltm Celestin, Salix Babylonia and Cinnamomum Camphora), shrubs (Crofton Weed and Ficus Macrocarpa), and herbaceous plants (Bidens Pilosa and Artemisia Annua). Due to its livability, this region has clear footprints of human activity and experiences frequent changes. It is the most economically active, densely populated, and urbanized region in Yunnan Province. This region is also typically selected to examine the interaction, results, and environmental impacts of human-land relationships. The geographic location and scope of the study area are shown in Figure 1.

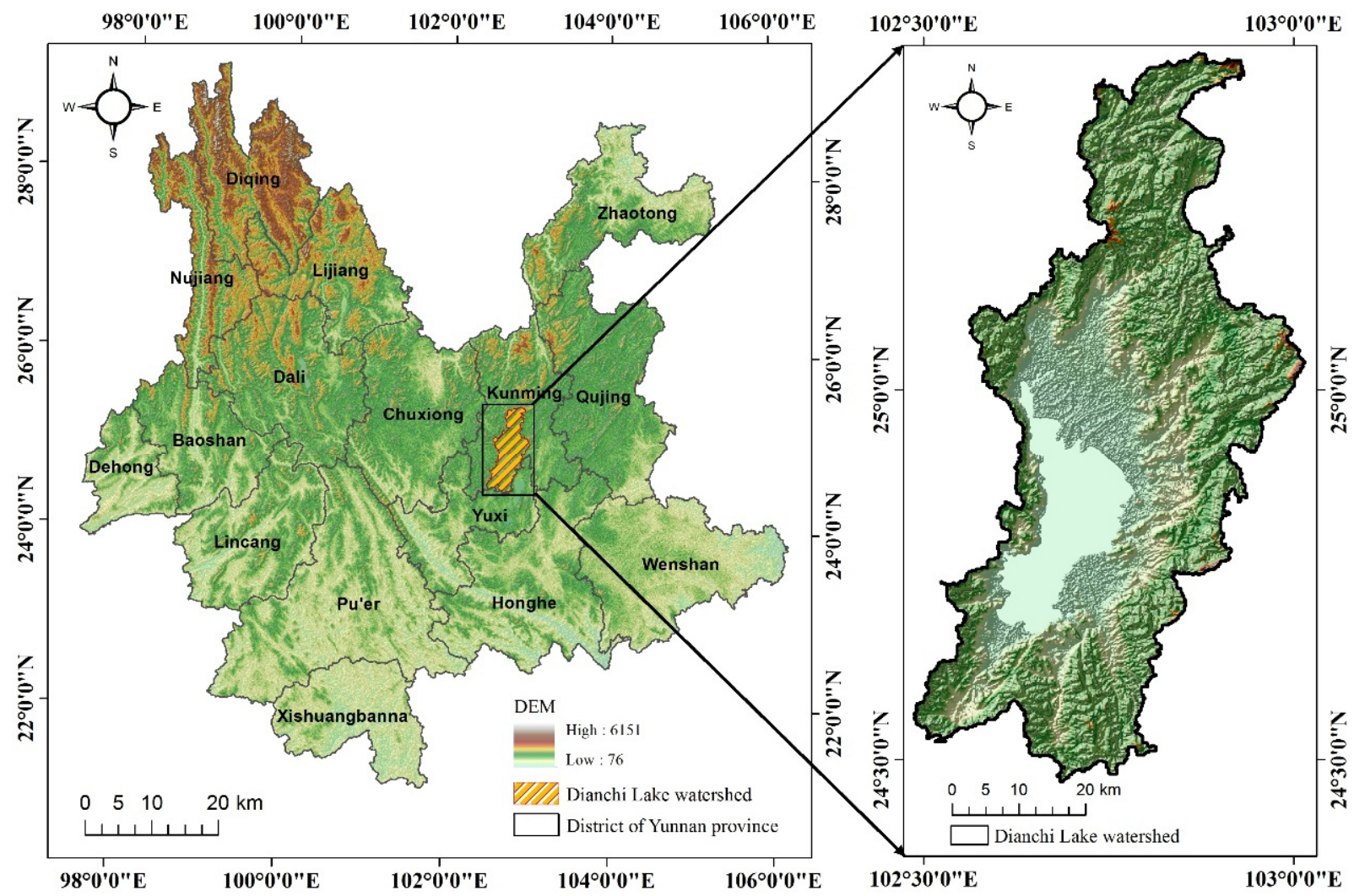

Figure 1. The geographical location of the Dianchi Lake watershed. 


\subsection{Data and Processing}

\subsubsection{Data Types and Sources}

This study used two main types of basic data: classification and driving force datasets. The land-use classification data were obtained by remote-sensing information extraction (The Classification And Regression Tree (CART) was selected as the classification extraction method). The remote-sensing imagery was obtained from the United States Geological Survey (USGS) and the image cloud content was less than 5\% as shown in Table 1.

The driving force data included information on the natural and cultural environments. The former mainly included data on aspects such as transportation networks, water systems, and administrative areas. This was sourced from the geospatial data cloud and the OpenStreetMap websites. Data on the cultural environment included information on population and socioeconomics and was sourced from the statistical yearbook of the corresponding year in Yunnan Province.

For convenience, the resolution of all raster data was set to $30 \mathrm{~m}$, and the scale was set to 1:250,000. As for the geography reference system, it was coordinated to “GCS_China_Geodetic_Coordinate_System_2000" and projected to CGCS2000_GK_CM _105E with Gauss-Kruger projection.

Table 1. Data source and parameters.

\begin{tabular}{|c|c|c|c|c|}
\hline Data & & Data Source or & neters & \\
\hline \multirow{5}{*}{ Remote sensing images } & Year & Satellite and sensor & Stripe & Resolution \\
\hline & 2006 & Landsat-5 TM & $129 / 42,129 / 43$ & $30 \mathrm{~m}$ \\
\hline & 2009 & Landsat-5 TM & $129 / 42,129 / 43$ & $30 \mathrm{~m}$ \\
\hline & 2013 & Landsat-8 OLI/TIRS & $129 / 43$ & $15 \mathrm{~m}$ \\
\hline & 2016 & Landsat-8 OLI/TIRS & $129 / 43$ & $15 \mathrm{~m}$ \\
\hline DEM & Year: 2016 & \multicolumn{2}{|c|}{ Source: USGS } & Resolution: $30 \mathrm{~m}$ \\
\hline Railway & Year: 2006, 2009, 2013, 2016 & \multirow{4}{*}{\multicolumn{2}{|c|}{ Source: Geospatial data cloud and OpenStreetMap }} & Scale: $1: 250,000$ \\
\hline Road & Year: 2006, 2009, 2013, 2016 & & & Scale: $1: 250,000$ \\
\hline River & Year: 2006, 2009,2013, 2016 & & & Scale: $1: 250,000$ \\
\hline Lake & Year: 2006, 2009, 2013, 2016 & & & Scale: $1: 250,000$ \\
\hline Population & Year: 2006, 2009, 2013, 2016 & \multirow{2}{*}{\multicolumn{2}{|c|}{ Source: Yunnan Provincial Statistics Bureau }} & Scale: $1: 250,000$ \\
\hline GDP & Year: 2006, 2009, 2013, 2016 & & & Scale: $1: 250,000$ \\
\hline
\end{tabular}

\subsubsection{Data Processing}

To construct a CA model of change, the data identified in Section 2.2.1 had to be processed and analyzed to meet modeling requirements. Table 2 details the model's data requirements, which may be divided into six categories comprising 19 types of data: two types of change data (classification and change rate--dependent variables) and 17 change driving force data (independent variables). The "Classification of Land Use Status GB/T21010-2017" and the geographic significance of Impervious Surface (IS) referring to artificial, impenetrable urban surfaces such as roofs, roads and plazas--were used to classify types, of which IS is a key indicator of the level of urbanization and its effects. types were divided into seven categories: cultivated land, forest, grassland, gardens, water bodies, impervious surfaces and unused land. In addition, the 16 driving forces included four spatial variables based on distance analysis, seven neighborhood variables handled by the neighborhood functions, three representing the unit's natural attributes and two representing its social attributes. Among them, the four distance-based variables were calculated from the vector data of lakes, water systems, roads, and railways in the study area. This was carried out using a distance analysis tool in the space analysis tool; variables processed by the seven neighborhood functions were obtained from statistics on the amount of each land type in the Moore neighborhood of $7 \times 7$ grid units in the remote-sensing image classification of the Dianchi Lake watershed. Three natural attribute 
variables (slope, slope direction, and elevation) were extracted from digital elevation model (DEM) data, and two social attribute variables (population density and gross domestic product (GDP)) were obtained from the statistical yearbook of Yunnan Province. To account for the impact of model operation efficiency and space scale, the cellular size was set at $200 \times 200 \mathrm{~m}$, and all required data were normalized. Table 2 details the specifics associated with the data and acquisition method.

Table 2. Spatial variables and acquisition approach.

\begin{tabular}{|c|c|c|}
\hline Data Category & Acquired Method & Range \\
\hline \multicolumn{3}{|c|}{ 1. Land-use data } \\
\hline Year of 2006, 2009, 2013, 2016 & Extraction of Remote-sensing images & $1-7$ \\
\hline \multicolumn{3}{|c|}{ 2. The area-weighted frequency of land-use change (AWFLUC) } \\
\hline AWFLUC from 2006 to 2016 & Overlay analysis & $0-1$ \\
\hline \multicolumn{3}{|c|}{ 2. Spatial distance variables } \\
\hline Distance to road $(\mathrm{X} 1)$ & & $0-1$ \\
\hline Distance to railway $(\mathrm{X} 2)$ & Distance analycis & $0-1$ \\
\hline Distance to river $(\mathrm{X} 3)$ & Distance anarysis & $0-1$ \\
\hline Distance to lake $(\mathrm{X} 4)$ & & $0-1$ \\
\hline \multicolumn{3}{|c|}{ 3. Land-use neighborhoods } \\
\hline Neighborhoods of impervious surface (X5) & & $0-1$ \\
\hline Neighborhoods of cultivated land (X6) & & $0-1$ \\
\hline Neighborhoods of water (X7) & & $0-1$ \\
\hline Neighborhoods of grass land (X8) & Neighborhood analysis & $0-1$ \\
\hline Neighborhoods of forestry land (X9) & & $0-1$ \\
\hline Neighborhoods of bear land (X10) & & $0-1$ \\
\hline Neighborhoods of garden land (X11) & & $0-1$ \\
\hline \multicolumn{3}{|c|}{ 4. Natural environmental variables } \\
\hline Slope $(\mathrm{X} 12)$ & & $0-1$ \\
\hline Aspect (X13) & Surface analysis & $0-1$ \\
\hline Elevation (X14) & & $0-1$ \\
\hline \multicolumn{3}{|c|}{ 5. Socio-economic variables } \\
\hline $\begin{array}{l}\text { Density of population (X15) } \\
\text { GDP (X16) }\end{array}$ & the statistical yearbook of Yunnan province & $0-1$ \\
\hline
\end{tabular}

\subsection{Methods}

\subsubsection{The Frequency of Change and Its Measurement}

The FLUC proposed in this paper may be expressed as the count and area of change within a specified period. The geographic meaning of FLUC is that it concurrently reflects the intensity and spatial distribution of change in a region based on three dimensions: time, space, and quantity. The computational process for FLUC and its area-weighted extension, the Area-Weighted Frequency of Land Use Change (AWFLUC) is shown in Figure 2, where (a) involves the classifications of different periods and the consequences of overlay analysis; (b) is the statistical counting of change from one type to another during any adjacent time; and (c) is the cumulative process of the frequency and area-weighted smoothing consequences from the beginning to the end of land use. The main variables and computing methods of AWFLUC are as follows:

(1) Statistical counting of change during an adjacent period

First, it has to be determined if changes between adjacent periods at the same position, and what the accumulated count of changes is. The calculation method is shown in Equation (1): 


$$
N_{k}^{t}=\left\{\begin{array}{ccc}
1 & \text { if }\left(P_{k} \cdot \text { Code }_{t} \neq P_{k} \cdot \text { Code }_{t+1}\right) & k \in\left[1, N_{\text {poly }}\right] \\
0 & \text { else } & t \in[1, m-1]
\end{array}\right.
$$

where $m$ is the number of periods of land use, which can form $(m-1)$ adjacent periods of change; $N_{\text {poly }}$ is the number of polygons formed after overlay analysis; $P_{k}$ is the $k$ th polygon; $C_{\text {Code }}$ represents the type at period $t$; $\operatorname{Code}_{i+1}$ represents the type at the time point next to period $t$; and $N_{k}^{t}$ indicates whether or not the land use has changed in the $k$ th polygon of period $t$. The computation rule for $N_{k}^{t}$ is: in the $k$ th polygon: if land use changes when the code value is inconsistent, then $N_{k}^{t}=1$; otherwise, $N_{k}^{t}=0$, indicating that land use has not changed.

(2) Measurement of the FLUC

The purpose of this step is to accumulate the frequency of land-use change in each polygon, which is the FLUC; the calculation method is shown in Equation (2):

$$
N_{k}=\sum_{t=1}^{m-1} N_{k}^{t} \quad k \in\left[1, N_{\text {poly }}\right]
$$

where $N_{k}$ is the accumulative frequency of land-use change in the $k$ th polygon within a certain period; the other variables have the same meaning as those in Equation (1).
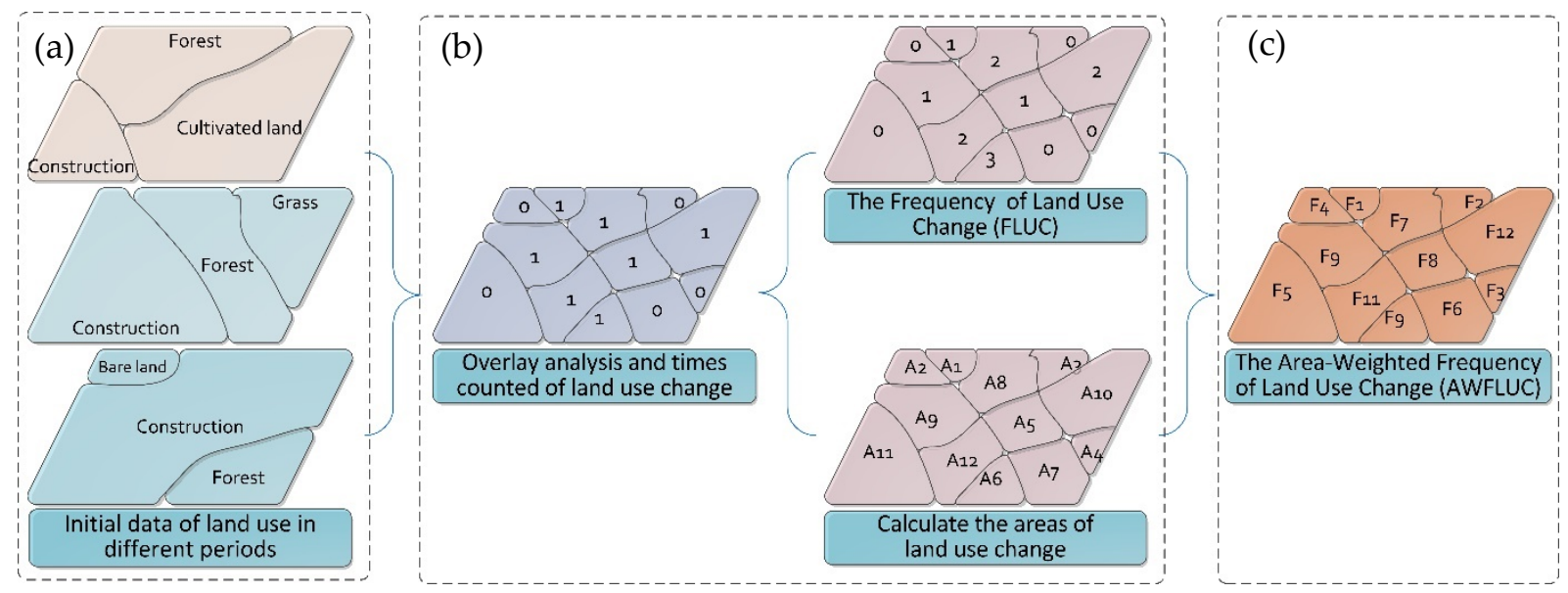

Figure 2. The computing flow of the area-weighted frequency of land-use change (AWFLUC). (a) The classifications of different periods and the consequences of overlay analysis; (b) The statisti-cal counting of change from one type to another during any adjacent time; (c) The cumulative process of the frequency and area-weighted smoothing consequences from the beginning to the end of land use.

(3) The area-weighted frequency of land-use change

The FLUC is able to reflect the speed of land-use change although it may disregard its impact. While the FLUC in some patches may be rapid, the area of change will be small; as such, this may not substantially influence land-resource development. For example, if a farmer needs a piece of land to cultivate seasonal vegetables for private use, the land cover change may occur at a high frequency; however, the changed area is usually insignificant. Therefore, the impact of land use on overall land resources from farmers is slight. In some patches, the FLUC is not rapid even though the area of change is large and could substantially affect land use. For example, airports and railway stations typically require a large area, and although the FLUC of this land use may not be high, it affects the land resources more than does the farmer's land use. This is because a considerable amount of cultivated land may be lost within a short time. Thus, the effect of the land-use change area should be considered in the FLUC to smoothen this indicator for greater responsibility. We 
improved the FLUC by using the land-use changed-area ratio as the weight, the AWFLUC, and its computation is shown in Equation (3):

$$
\left\{\begin{array}{l}
\omega_{k}=\frac{S_{\text {area }}^{k}}{S_{\text {area }}} \\
F_{\text {final }}=\sum_{k=1}^{N_{\text {poly }}} \omega_{k} N_{k}
\end{array}\right.
$$

where $F_{\text {final }}$ is the AWFLUC of a given space unit; $S_{\text {area }}$ is the area of the space unit; $S_{\text {area }}^{k}$ is the area of the $k$ th polygon in the space unit; and $\omega_{k}$ is the AWFLUC in the $k$ th polygon.

\subsubsection{Cellular Space Partition Based on Dual-Constrained Spatial Clustering}

The basis of the cellular space partition is the similarity of geographic attributes and locations represented by the cell. Cluster analysis is the main method used to detect and evaluate this similarity [34]. Many geographic phenomena contain two distinct attributes: spatial and non-spatial. The former refer to properties such as position and relationship; the latter refer to features unrelated to space, such as population density, per capita gross national product, and gross industrial and agricultural output. The influence of these two attributes on distance should be comprehensively considered in the clustering analysis of geographic phenomena. Traditional clustering algorithms divide the spatial and nonspatial attributes of geographic phenomena. However, the same class of spatial objects needs to have high compactness in spatial characteristics and a high degree of similarity in non-spatial characteristics during the similarity calculation for geographic phenomena. This study used a dual-constraint criterion spatial-clustering method proposed by Ke Xinli et al. $[29,30,32]$ to divide cellular space. This aimed to achieve an optimal dynamic equilibrium between compactness in the spatial domain and similarity in the non-spatial domain of every partition.

The key to spatial clustering with dual-constraint criteria is redefining the distance. Given a set of spatial objects, $S=\left\{\mathrm{O}_{1}, \mathrm{O}_{2}, \ldots, O_{n}\right\}$, any object, $\mathrm{O}_{i} \in S$, has two attribute domains: spatial and non-spatial. The dual-constrained space-clustering divides the object set, $S$, into different clusters; as such, each cluster forms a compact area in the spatial domain and maximizes the similarity in the non-spatial domain. To address a spatial geometric distance that was insufficient for dual-constrained spatial clustering, a generalized Euclidean distance was used as the clustering statistic as opposed to spatial geometric distance. This may be defined as follows [35]:

$$
\begin{gathered}
D_{i j}=w_{p} \sqrt{\left(x_{i}-x_{j}\right)^{2}+\left(y_{i}-y_{j}\right)^{2}}+w_{a} \sqrt{\sum_{k=1}^{m} w_{k}\left(z_{i k}-z_{j k}\right)^{2}} \\
w_{p}+w_{a}=1 \\
\sum_{k=1}^{m} w_{k}=1
\end{gathered}
$$

where $D_{i j}$ is the generalized Euclidean distance between points $i$ and $j ;\left(x_{i}, y_{i}\right)$ and $\left(x_{j}, y_{j}\right)$ are the spatial coordinates of points $i$ and $j$, respectively; $Z_{i k}$ and $Z_{j k}$ are the $k$ th attribute values of points $i$ and $j$, respectively; $m$ is the attribute number of the point group; $w_{p}$ and $w_{a}$ are the importance of spatial distance and non-spatial attribute similarity in generalized Euclidean distance, respectively; and $w_{k}$ is the importance of each attribute in the spatial data set. To determine the weight value, a set of weight values was established and model simulation accuracy was analyzed under different weights. The weight value was deemed optimal when model accuracy was at its peak. When the similarity of the non-spatial characteristics of land-use change was measured, the amount of land-use change was typically selected for assessment. However, the amount of land-use change only reflected the magnitude of land-use change in two periods; it could not depict the degree of human-land interaction. Therefore, the AWFLUC was selected to identify the spatial heterogeneity of land-use change as it is an important index that can reflect the degree of human-land interactions. 
By using the AWFLUC, more reasonable non-spatial attribute similarity for cellular space partition was attained.

\subsubsection{ANN-CA Model Construction Method of Land-Use Change}

The method proposed by Li Xia et al. [23,24] was used to construct a land-use change CA model based on an ANN, as shown in Figure 3. Model construction may be divided into two parts: ANN-based land-use change conversion-rule mining, and an ANN-CA model simulation. First, land-use types and driving factors were used as input parameters for NN training. The conversion probability of different land-use types in each partition was obtained through network training based on the results of cellular-space partitioning. Then, the obtained transition probability served as the basis for cellular-state transformation to determine the state (land type) of the cellular space at the next point in time. With the repeated iteration, the change in land-use state with time was simulated. Finally, when the iterations met the set termination conditions, the simulation ceased, and the results were checked for accuracy (overall accuracy and Kappa coefficient), to verify model quality. To compare the role of partitioned CA and key attributes in cellular partitioning, the training data were divided into three categories: overall training without the AWFLUC factor, partition training without the AWFLUC factor and partition training with the AWFLUC factor. The training sample set was randomly generated using software. Following data verification of the trained model, the weight value and bias parameter of each variable of the NN obtained were saved. The land-use type that the cellular state would convert into at the next time point was determined by the roulette selection method. This meant the conversion probability was designed as a digital roulette, which would generate a random number each time. Then, the cellular state would be converted to the land type corresponding to the conversion probability of random number matching at the next time point. The cellular-state change determined by roulette in this study was more in line with the randomness of the land-use change process, which helped to improve the authenticity of the simulation.

Using ANN to mine the rules of cellular-state transition was key, involving a multi-step core process. First, the standardized land-use type and its driving factors $\left(X_{i}\right)$ formed the input layer (training data) of the ANN, and this input determined the land-use conversion probability of the $k$ th unit at time $t$. Second, the hidden layer received the data from the input layer, and the signal of the $j$ th neuron at time $t$, of this unit $\left(\right.$ net $\left._{i}(k, t)\right)$, was obtained through training. Lastly, the hidden layer generated a certain response value to these signals, which was converted into the final conversion probability $(P(k, t, l))$ by the response function and transmitted to the output layer. The calculation methods for these key variables are as follows:

$$
\begin{aligned}
\operatorname{net}_{j}(k, t) & =\sum_{i} w_{i, j} x_{i}(k, t) \\
P(k, t, l) & =\sum w_{j, l} \frac{1}{1+e^{-n e t_{j}(k, t)}}
\end{aligned}
$$

where $x_{i}(k, t)$ represents the driving factor variables of the $k$ th unit at time $t ; w_{i, j}$ represents the weight between the input layer and the hidden layer; $(P(k, t, l))$ represents the probability of the $k$ th cell being converted from its current state to $l$ at time, $t$; and $w_{j, l}$ is the weight value of the $j$ th neuron in the hidden layer and the $l$ th neuron in the output layer. 


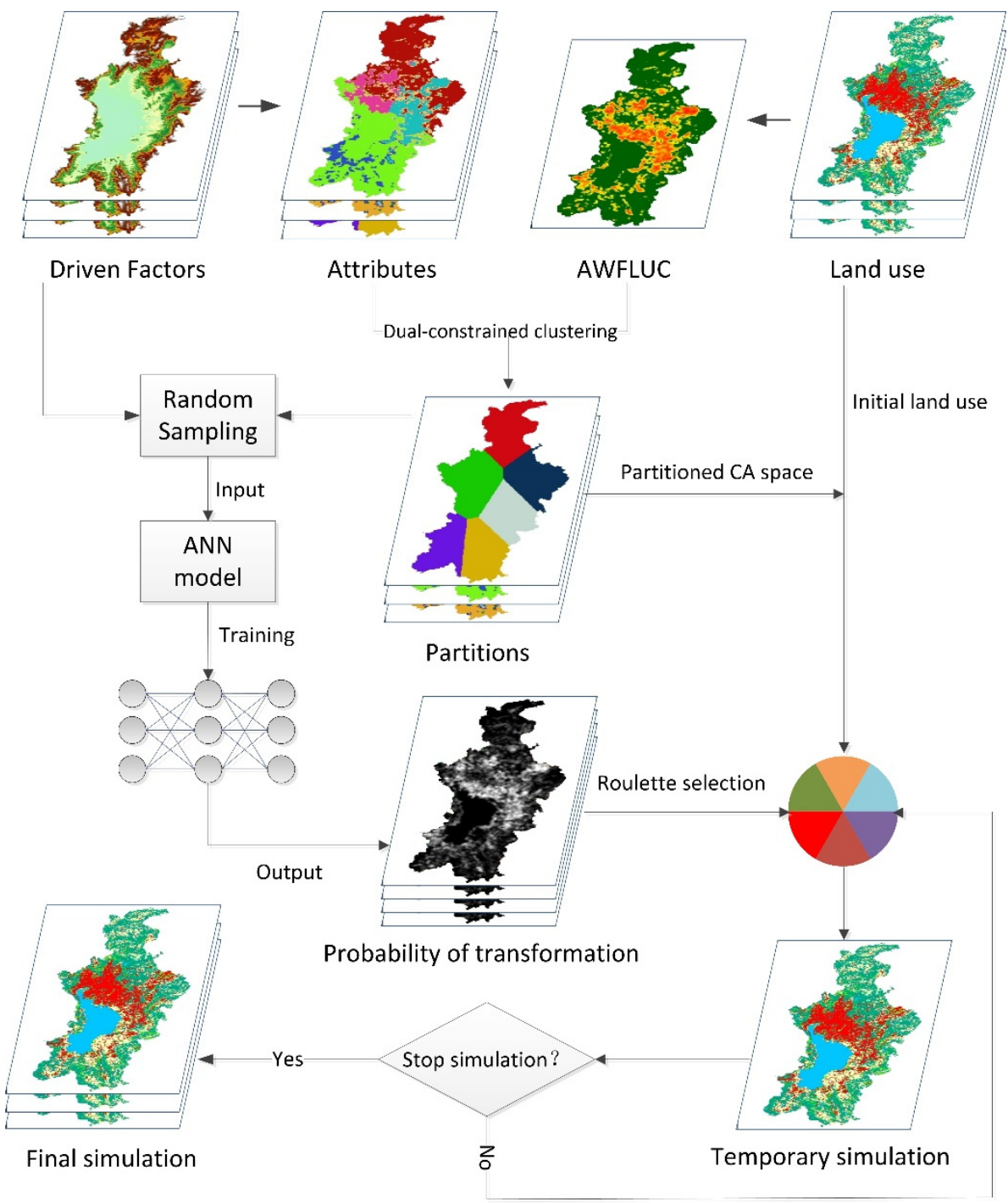

Figure 3. ANN-CA Model Flow Chart.

\section{Results}

\subsection{Cellular Space Partition Results}

The land-use change similarity partition results for the study area were obtained using the dual-constraint partition method in conjunction with land-use classification, the spatial geometric division based on the Thiessen polygon, fundamental attributes (population density, GDP, slope, aspect, and elevation), and the AWFLUC of the study area from 2006 to 2016 (see Figure 4). Figure 4 shows that partitioning the cellular space using the dual-constraint method ensured cellular compactness in the spatial domain, and did not lose similarity in the non-spatial domain. As such, this may better reflect the spatial differentiation law of land-use change. The weight had a degree of influence on the partitioning effect of the dual-constrained partitioning method: when $\mathrm{w}_{\mathrm{p}}=0$ and $\mathrm{w}_{\mathrm{a}}=1$, it represented partitioning only according to the property. Conversely, the partitioning according to the space distance, and the inputs between the two set values represented a dual-constraint partition. Following a visual analysis and comparison of the partition results under different weights, the weight of the partition results was finally determined to be: $w_{p}=0.5$ and $w_{a}=0.5$. 

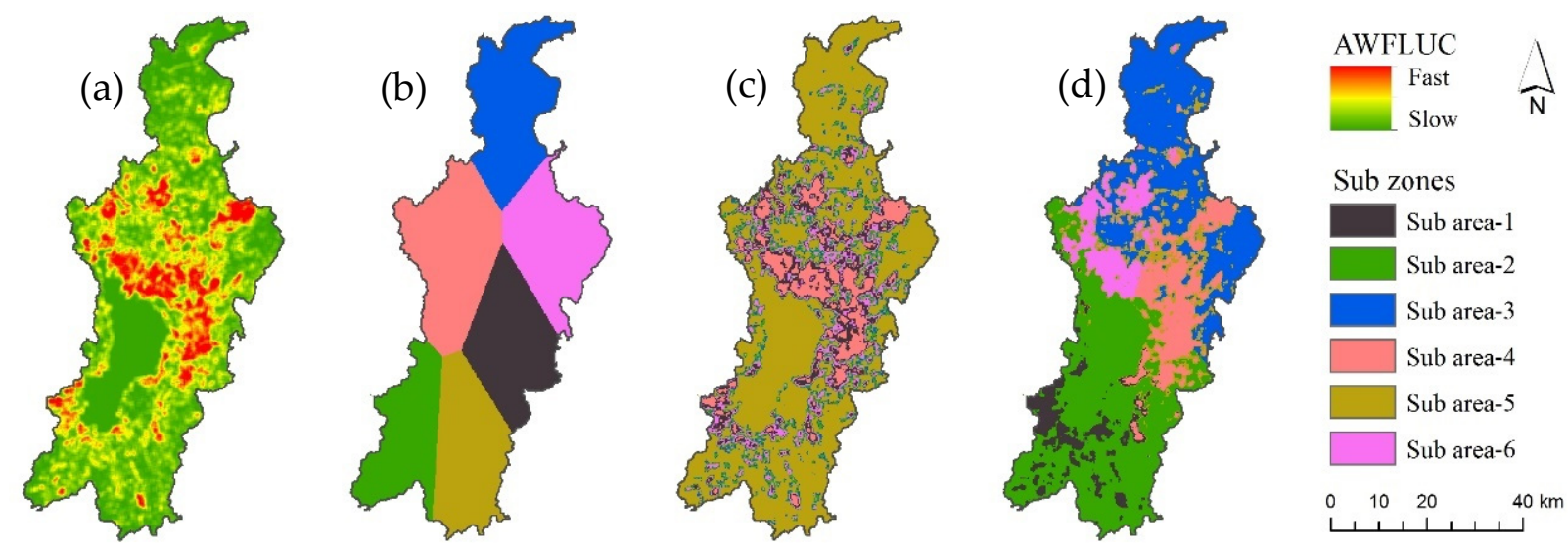

Figure 4. Land-use changes from 2006 to 2016, partition with different weights. (a) The frequency of land-use change (AWFLUC); (b) Partition based on spatial distance; (c) Dual-constrained partition without considering AWFLUC; (d) Dualconstrained partition with considering AWFLUC.

\subsection{Cellular Conversion Rules Acquisition Based on ANN}

The ANN training datasets of four different periods were generated, consisting of 4000 random sampling points, of which 2000 were used for training and 2000 were used to verify the training results. These datasets were based on the four different periods of land-use data and driving factors in the study area, and the three schemes: no partition, partition according to land-use change, and partition according to land-use change rate. When the contrast accuracy of the training and verification datasets reached the set threshold, it signified that the training accuracy met the requirements; consequently, the ANN discontinued the iterative process and output the training results (weights and biases). Table 3 presents the accuracy valuation of training: loss rates were relatively low, and the ANN model satisfied the requirements for conversion-rule mining.

Table 3. The accuracy valuation of ANN model.

\begin{tabular}{cccc}
\hline \multirow{2}{*}{ Model Index } & \multicolumn{3}{c}{ Loss Rate } \\
\cline { 2 - 4 } & $\mathbf{2 0 0 6 - 2 0 0 9}$ & $\mathbf{2 0 0 9 - 2 0 1 3}$ & $\mathbf{2 0 1 3 - 2 0 1 6}$ \\
\hline Mode I & 0.39162 & 0.37613 & 0.34464 \\
Model II & 0.33429 & 0.30922 & 0.27666 \\
Model III & 0.33422 & 0.30890 & 0.28092 \\
\hline
\end{tabular}

Note: Model I: Non-partitioned CA model; Model II: Ordinary partitioned CA model; Model III: AWFLUC constrained partitioned CA model.

Based on the ANN training results, the probability maps of the conversion of each land-use type for each CA model were calculated for each simulation period: 2006-2009, 2009-2013, and 2013-2016. The probability maps in Figure 5 are examples of Model III; these maps determine the probability that one land-use type may switch to another. 


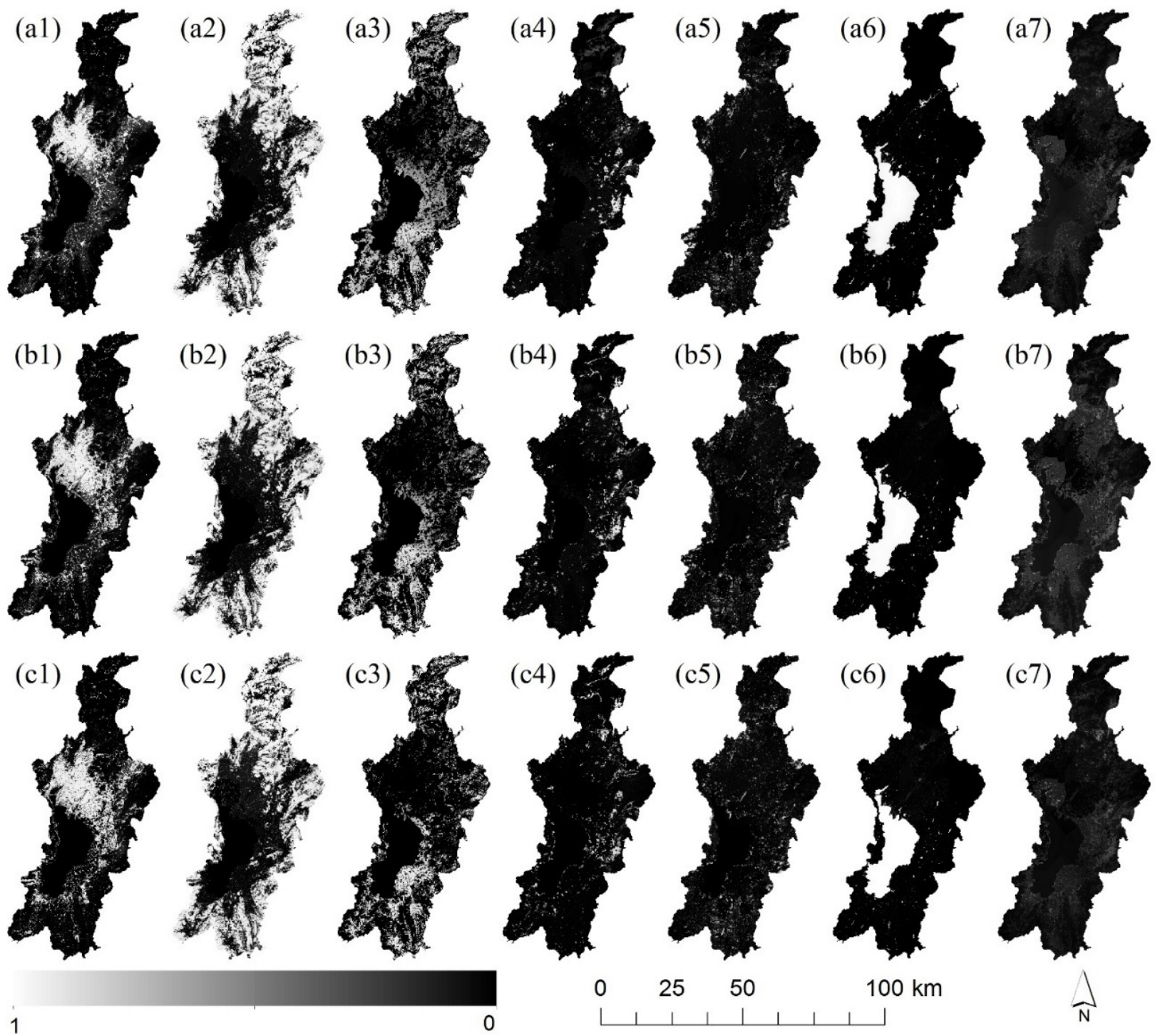

Figure 5. The probability maps $(x 1-x 7)$ are the transition probabilities of seven land-use types, which are, respectively, IS, forest, cultivated land, grassland, garden, water area and bare land. Here, $\mathrm{x}$ is a, b or c, which refers to, respectively, 2006-2009, 2009-2013 or 2013-2016.

\subsection{Land-Use Dynamic Simulation Results and Accuracy Test}

Once the AWFLUC was calculated for 2006-2009, 2009-2013, and 2013-2016 and the total AWFLUC was determined for the 10 years, the land-use change processes for each time period were simulated using the ANN-CA model. The simulation was based on the CA conversion rules under three different cellular-space partitioning schemes, which are shown in Figure 6. For ease of understanding, three abbreviated aliases were used to represent the three types of CA models used in this study. Model I represents the non-partitioned CA model; Model II represents the ordinary dual-constrained partitioned CA model (without considering AWFLUC); and Model III represents the dual-constrained partitioned CA model considering AWFLUC. 


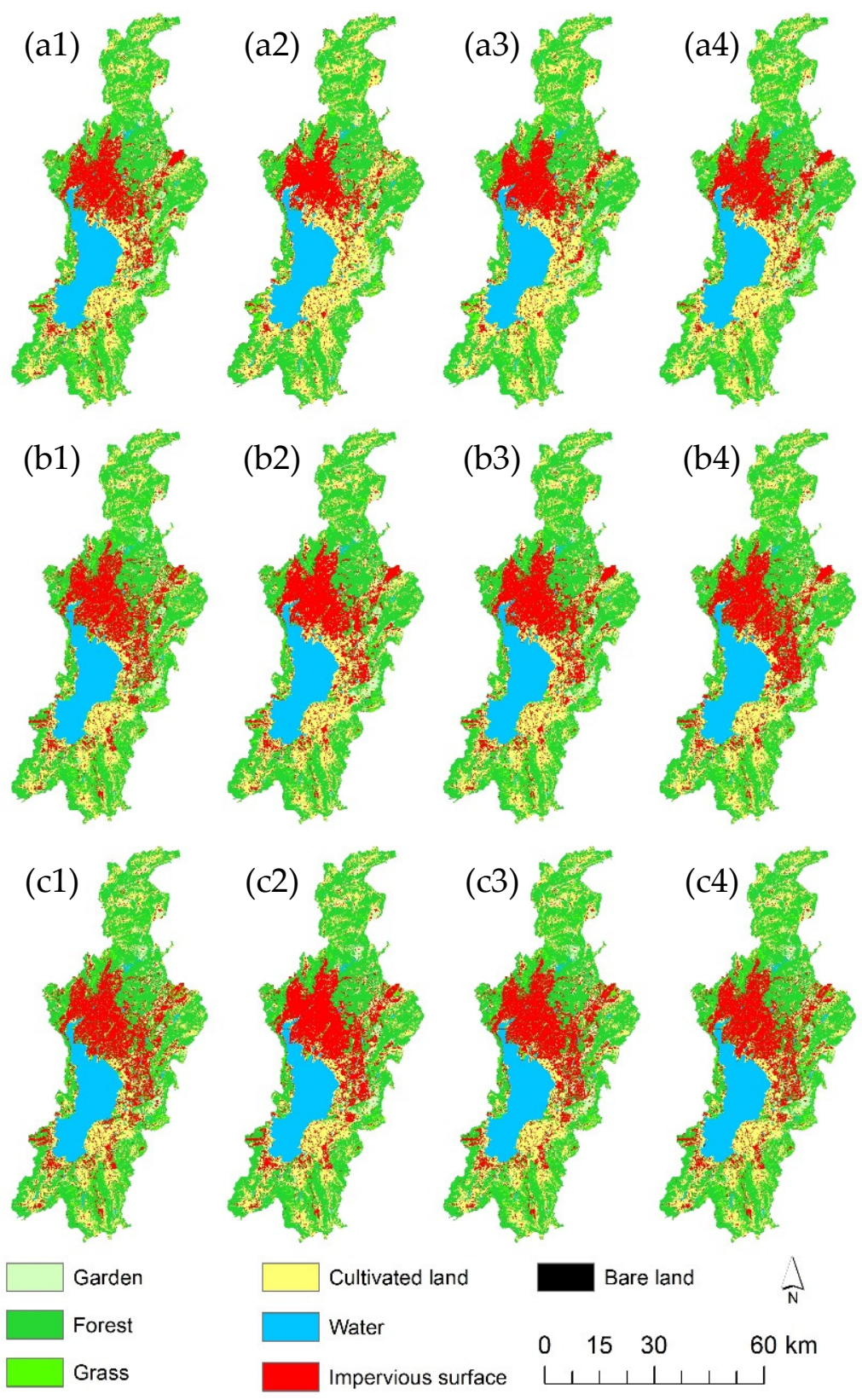

Figure 6. Comparison of simulation results with different CA partition. (x1) is the actual land use, and (x2-x4) are the simulation results of Model I, Model II and Model III. Here, " $\mathrm{x}$ " is a, b or c, which means the period of 2006-2009, 2009-2013 and 2013-2016, respectively.

To verify the correctness and reliability of the simulation model, the Kappa coefficient and overall accuracy were used to evaluate model quality. The Kappa coefficient was used to measure the consistency between simulation results and reality. When it ranges from -1 to 1 , the result is usually between zero and one. When Kappa $=1$, the simulation result is completely consistent with reality; when Kappa $\geq 0.75$, the consistency is high; and when Kappa $\leq 0.4$, the consistency is poor and the simulation result is not ideal. The Kappa coefficient and the overall accuracy of the results from each simulation year were determined at a sampling rate of $20 \%$. Table 4 shows that the simulation accuracy of the partitioned CA models was significantly better than the non-partitioned model (Kappa coefficient increased by a maximum of $>9 \%$, and the maximum overall accuracy exceeded $14 \%)$; as such, the quality of the partitioned model had significantly improved. Compared with Model II, the simulation accuracy of Model III was also found to improve (Kappa coefficient increased by a maximum of $>6 \%$, and overall accuracy increased by a maximum 
of $>3 \%$ ). The experimental and precision analysis results confirmed that the hypothesis proposed in this research is scientific and effective.

Table 4. The simulation accuracy evaluation of three CA models in three periods.

\begin{tabular}{|c|c|c|c|c|c|c|c|c|c|c|c|c|}
\hline \multirow{3}{*}{ Period (Year) } & \multirow{2}{*}{\multicolumn{2}{|c|}{ Model I }} & \multirow{2}{*}{\multicolumn{2}{|c|}{ Model II }} & \multirow{2}{*}{\multicolumn{2}{|c|}{ Model III }} & \multicolumn{6}{|c|}{ AAUD } \\
\hline & & & & & & & \multicolumn{2}{|c|}{ I vs. II } & \multicolumn{2}{|c|}{ II vs. III } & \multicolumn{2}{|c|}{ I vs. III } \\
\hline & OA & K & OA & $\mathbf{K}$ & OA & K & OA & K & OA & $\mathbf{K}$ & OA & $\mathbf{K}$ \\
\hline 2006-2009 & 0.8301 & 0.7716 & 0.8606 & 0.8133 & 0.8833 & 0.8448 & $3.68 \%$ & $5.41 \%$ & $2.64 \%$ & $3.87 \%$ & $14.48 \%$ & $9.49 \%$ \\
\hline 2009-2013 & 0.8477 & 0.7959 & 0.8687 & 0.8133 & 0.9007 & 0.8680 & $2.48 \%$ & $2.19 \%$ & $3.68 \%$ & $6.72 \%$ & $13.17 \%$ & $9.05 \%$ \\
\hline 2013-2016 & 0.8616 & 0.8151 & 0.8952 & 0.8602 & 0.9187 & 0.8920 & $3.90 \%$ & $5.54 \%$ & $2.63 \%$ & $3.69 \%$ & $12.72 \%$ & $9.44 \%$ \\
\hline
\end{tabular}

Note: Model I: Non-partitioned CA model; Model II: Ordinary partitioned CA model (without considering AWFLUC); Model III: AWFLUC constrained partitioned CA model; OA: Overall Accuracy; K: Kappa coefficient. AAUD: Analysis of accuracy ups and downs.

\subsection{Land-Use Dynamic Simulation Results and Accuracy Test}

To test the sensitivity of the AWFLUC to the space partition of CA, three typical areas that had the same area but differed in land-use change frequency (high, medium, or low) were selected. The method used in this test followed a multi-step process. First, in the three selected test areas, land-use change was simulated by Models I, II, and III. Second, the influence of AWFLUC on the CA model of land-use change was evaluated by analyzing the simulation accuracy of the three models in the same testing area. Figures 7 and 8 present the land-use change simulations from each model in the three testing areas, and Table 5 presents the analysis of their accuracy.

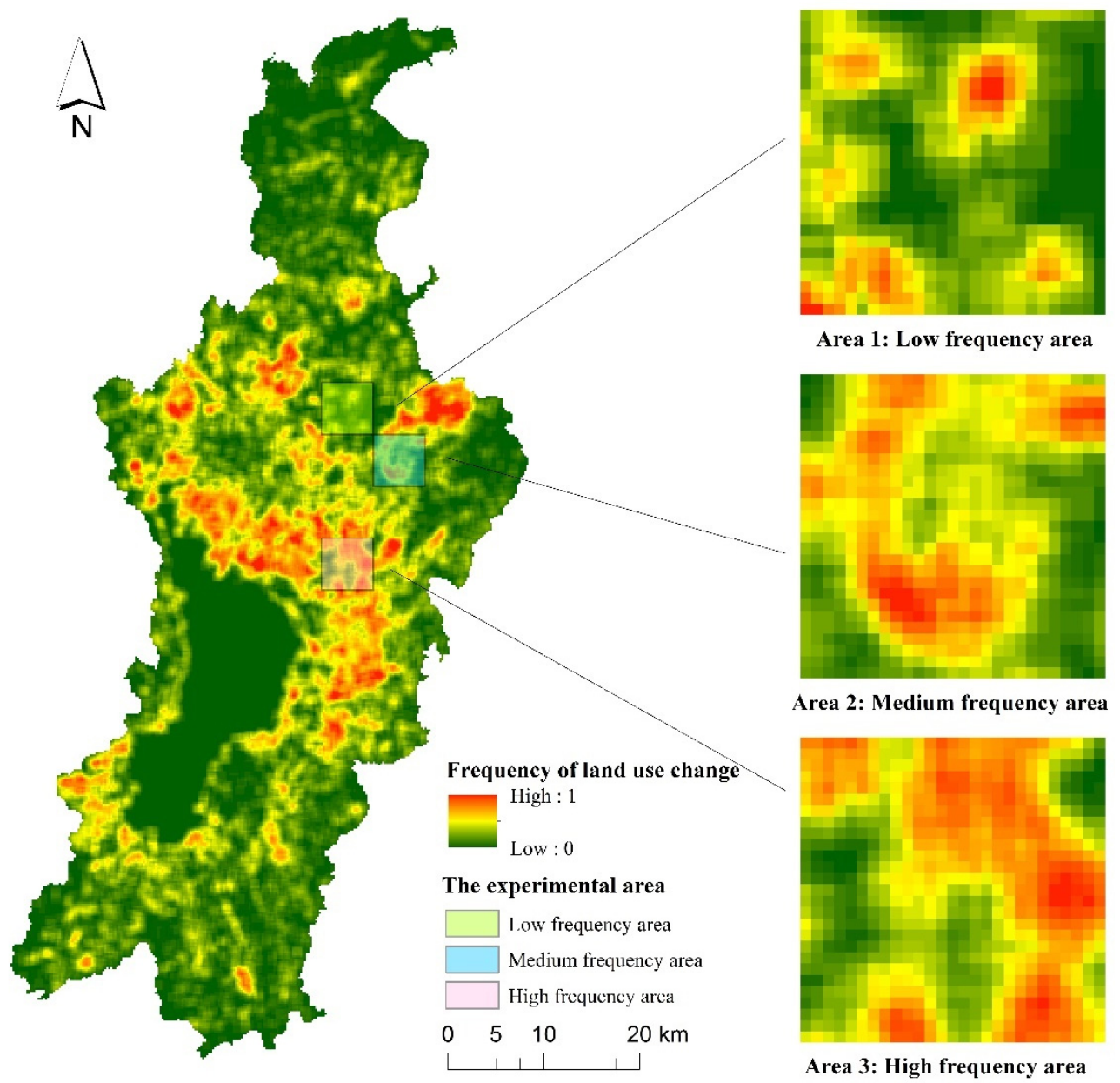

Figure 7. Three testing areas to analyze the sensitivity of AWFLUC. 

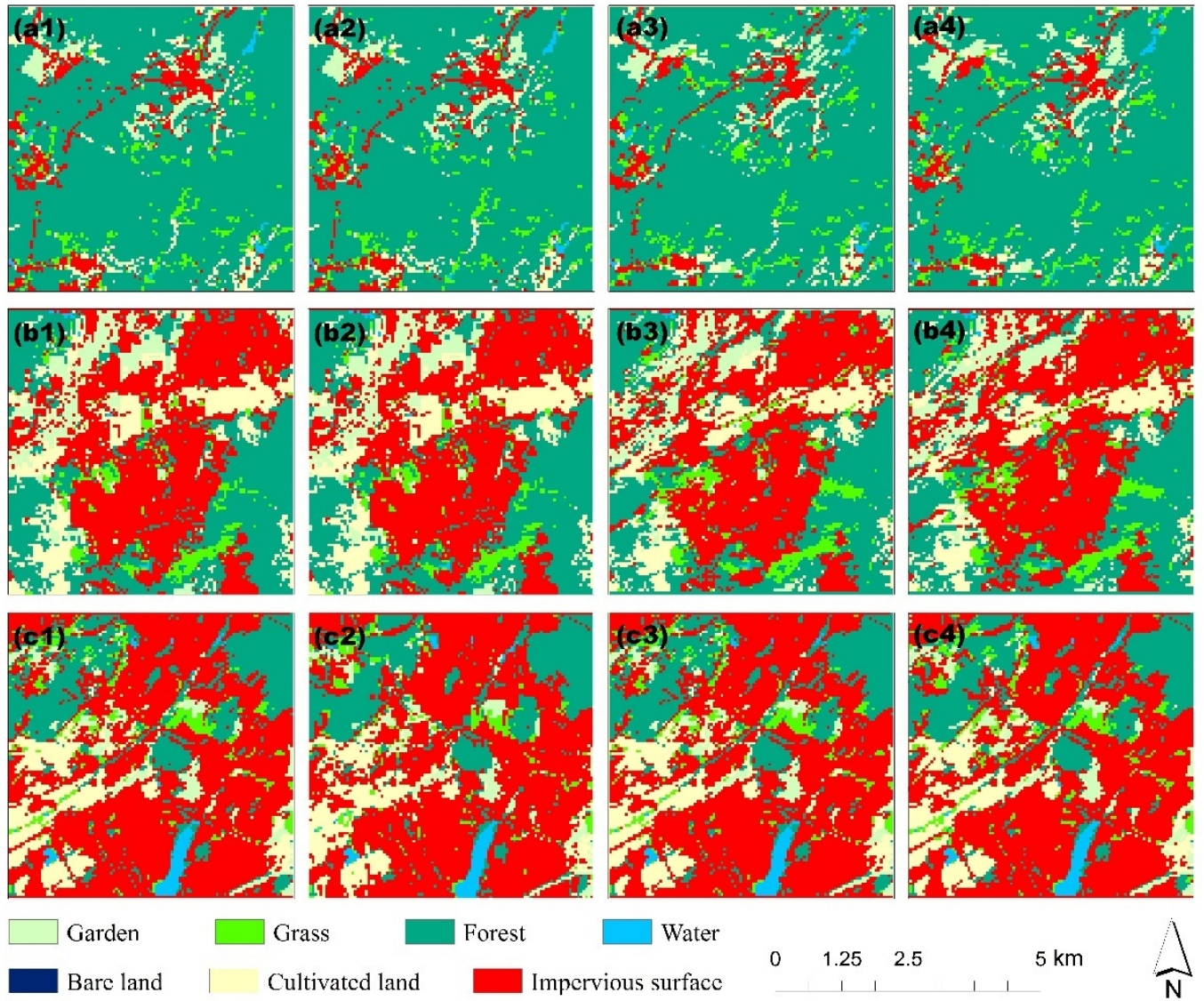

Cultivatcd land

Forest

Water

Impervious surface

$\begin{array}{lll}0 & 1.25 & 2.5\end{array}$

$5 \mathrm{~km}$

Figure 8. The simulation results of using three different CA models in three testing areas. (a1) Initial land use in Area 1; (a2) Simulation result by Model I in Area 1; (a3) Simulation result by Model II in Area 1; (a4) Simulation result by Model III in Area 1; (b1) Initial land use in Area 2; (b2) Simulation result by Model I in Area 2; (b3) Simulation result by Model II in Area 2; (b4) Simulation result by Model III in Area 2; (c1) Initial land use in Area 3; (c2) Simulation result by Model I in Area 3; (c3) Simulation result by Model II in Area 3; (c4) Simulation result by Model III in Area 3.

The rows in Table 5 depict the simulation accuracies of the CA model and the variations under the three partitioning strategies of the CA space. As such, the influence of the three strategies on the CA model may be analyzed from the row perspective. Table 5 shows that the overall accuracy and Kappa coefficient of simulation in the three testing areas changed with model selection, thereby exhibiting clear improvements in accuracy. The overall accuracy and Kappa coefficient of the simulation results obtained using Model II improved by 8.57 and $10.72 \%$, respectively, compared with Model I, and the overall accuracy and Kappa coefficient of the simulation results obtained using Model III improved by a maximum of 13.51 and $11.07 \%$, respectively over Model II. Furthermore, there was improved simulation accuracy using Model III in Area 2 (with medium AWFLUC) and Area 3 (with high AWFLUC) compared to Area 1 (with low AWFLUC). As such, these results indicate that the CA space was sensitive to AWFLUC. In other words, AWFLUC was conducive to identifying the spatial heterogeneity of land-use evolution more accurately, thus optimizing the division strategy of the CA space.

Second, the column perspective of the table reflects the influence of AWFLUC on three different partitioned CA models. The results demonstrated that, with an increase in AWFLUC from Areas 1 to 3, the three CA models experienced a downward trend in accuracy to varying degrees. This showed that human-land interaction may to a certain extent be described by AWFLUC; this is because the increase in AWFLUC indicated that the intensity of human-land interactions was rising. This increased interaction elevated the complexity of land-use evolution and the difficulties associated with the land-use change 
simulation using the CA model; as such, this led to a decrease in simulation accuracy. Among the three models, Model I showed the largest fluctuation in simulation accuracy (overall accuracy was reduced by up to $6.69 \%$, and the Kappa coefficient was reduced by up to $8.24 \%$ ), while Model III experienced the smallest fluctuation (overall accuracy was reduced by up to $0.29 \%$, and the Kappa coefficient was reduced by up to $0.35 \%$ ). This may have indicated that the partitioned CA model had better stability than the non-partitioned CA model. This may have been because the AWFLUC had a better ability to identify the spatial heterogeneity of land-use evolution. As such, the AWFLUC-constrained partition of the CA space was able to resemble the actual evolution of landscape pattern more closely, thus improving the simulation accuracy of land-use change through the CA model.

Table 5. The accuracy evaluation and analysis of three CA models in testing areas.

\begin{tabular}{|c|c|c|c|c|c|c|c|c|c|c|c|c|c|}
\hline & & \multirow{2}{*}{\multicolumn{2}{|c|}{ Model I }} & \multirow{2}{*}{\multicolumn{2}{|c|}{ Model II }} & \multirow{2}{*}{\multicolumn{2}{|c|}{ Model III }} & \multicolumn{6}{|c|}{ AAUD } \\
\hline & & & & & & & & \multicolumn{2}{|c|}{ I vs. II } & \multicolumn{2}{|c|}{ II vs. III } & \multicolumn{2}{|c|}{ I vs. III } \\
\hline & & OA & $\mathbf{K}$ & OA & $\mathbf{K}$ & OA & $\mathbf{K}$ & OA & $\mathbf{K}$ & OA & $\mathbf{K}$ & OA & $\mathbf{K}$ \\
\hline \multicolumn{2}{|c|}{ Area 1} & 0.9041 & 0.885 & 0.9198 & 0.9038 & 0.9346 & 0.9215 & $1.74 \%$ & $2.12 \%$ & $1.61 \%$ & $1.96 \%$ & $5.60 \%$ & $4.12 \%$ \\
\hline \multirow{2}{*}{\multicolumn{2}{|c|}{$\begin{array}{l}\text { Area } 2 \\
\text { Area } 3\end{array}$}} & 0.8296 & 0.7956 & 0.9007 & 0.8809 & 0.9031 & 0.8837 & $8.57 \%$ & $10.72 \%$ & $0.27 \%$ & $0.32 \%$ & $13.51 \%$ & $11.07 \%$ \\
\hline & & 0.8891 & 0.867 & 0.9047 & 0.8857 & 0.9319 & 0.9183 & $1.75 \%$ & $2.16 \%$ & $3.01 \%$ & $3.68 \%$ & $7.49 \%$ & $5.92 \%$ \\
\hline \multirow{3}{*}{ AAUD } & 1 to 2 & $-6.69 \%$ & $-8.24 \%$ & $-0.44 \%$ & $-0.54 \%$ & $-3.09 \%$ & $-3.77 \%$ & & & & & & \\
\hline & 1 to 3 & $-1.66 \%$ & $-2.03 \%$ & $-1.64 \%$ & $-2.00 \%$ & $-0.29 \%$ & $-0.35 \%$ & & & & & & \\
\hline & 2 to 3 & $7.17 \%$ & $8.97 \%$ & $0.44 \%$ & $0.54 \%$ & $3.19 \%$ & $3.92 \%$ & & & & & & \\
\hline
\end{tabular}

Note: Model I: Non-partitioned CA model; Model II: Ordinary partitioned CA model (without considering AWFLUC); Model III: AWFLUC constrained partitioned CA model; Area 1: Low-frequency area of land-use change; Area 2: Medium-frequency area of land-use change; Area 3: High-frequency area of land-use change; OA: Overall Accuracy; K: Kappa; AAUD: Analysis of accuracy ups and downs.

\section{Discussion}

Spatial heterogeneity is a common geographic phenomenon in land-use evolution. When a CA model is used to simulate land-use change, it is necessary to consider the influence of spatial heterogeneity on key processes, such as the selection of transformation rules and scale [36]. Although double-constrained spatial clustering is an effective method of dividing cellular space, it only provides a computational framework; it cannot explain the differences in land-use from the internal mechanism. To solve the above problem, this paper put forward the idea of adding indicators that could better characterize the spatial heterogeneity characteristics of land-use change within the double-constraint calculation method for dividing cellular space. Therefore, an index called the "Area-Weighted Frequency of Land-use Change (AWFLUC)" was proposed to identify the spatial heterogeneity of land-use change and improve the rationality of cellular-space partition. As a result, two dual-constrained methods--one with and one without the influence of AWFLUC--were proposed for dividing the CA space, and the consequences of two methods were compared and analyzed. Moreover, the validity of these methods was verified by simulating land-use change in the Dianchi Lake watershed through verification of model accuracy. The analysis suggested that the dual-constrained method of cellular space accounts for the spatial adjacency relationship and the similar attributes of land units. These features may be the basis for the observed improvements in simulation accuracy from using the CA model in land-use change [29,30,32]. However, this method also possesses some degree of subjectivity when it assigns weight to the similarity of space and attribute features. Therefore, it is recommended that future research focus on determining the weight more reasonably or identifying a better method of cellular space partitioning. At present, great progress in the quantitative detection of spatial heterogeneity was made. Using detection tools such as "Geodetector" [28] to identify the spatial heterogeneity of land-use change offers a probable way of determining the weight of the similarity of space and attributive features more objectively. 
The AWFLUC is an important indicator for measuring human-land interactions; however, it may be influenced by the density of the time interval of original land-use data, such as the data acquisition time of remote-sensing imagery. The higher the temporal resolution of land-use classification data collections, the larger the AWFLUC. In contrast, if the temporal resolution of data collection had been low, it would have been difficult to show human-land interactions. Limited by the availability of raw data, the minimum temporal resolution of the original land-use data is three years, and the maximum is four. The temporal resolution of the data was uneven, and the span was relatively high. It is not known whether the calculated land-use change frequency was able to reflect the intensity of human-land interactions over a 10-year period (2006-2016) objectively. Therefore, future research to determine the AWFLUC, will need to address the effect of the original data acquisition period. It is evident that increasing the temporal resolution of land use in data updating environmental permits is conducive to improving the reliability of the AWFLUC.

\section{Conclusions and Further Work}

This study used ANNs and the CA model to construct an ANN-CA model, based on the cellular-space partition theory and the dual-constrained partition method. This model was suitable for simulating the land-use change process in the Dianchi Lake watershed. Through the analysis and verification of the test results, the main conclusions are the following:

(1) The partitioned CA based on dual-constrained spatial clustering significantly improved the simulation accuracy of the land-use change model. Cellular-space division based on dual-constrained spatial clustering guaranteed cellular compactness in the spatial domain, and accounted for its similarity in the non-spatial domain. Thus, it was able to better reflect the spatial differentiation law of the cellular space. The experimental results showed that the simulation accuracy of the partitioned CA model based on dualconstrained spatial clustering was significantly higher than that of the uniform regular CA (non-partitioned CA); and

(2) The AWFLUC is an effective index for identifying the differentiation law of cellular space. In this study, using AWFLUC as the attribute, the dual-constrained method combined with the spatial geographic location was used to partition the cellular space. This properly solved the problem of an inconsistent evolution process and the results of geographic cellular space; as such, the impact of this problem on the accuracy of the CA model was reduced. The simulation process was able to better reflect the relationships among cellular elements and their own attributes.

In summary, there is an influence from spatially heterogeneous regional development on the differentiation of cellular space, and this influence is controllable. The cellular-space partitioning method and the partitioned ANN-CA model can greatly improve the accuracy of the land-use change simulations, where the degree of improvement was significant. It is recommended that future research focus on the following:

First is the weights of cellular spatial regionalization. In this study, these were based on dual-constrained spatial clustering that were mainly determined by empirical and visual interpretation methods. These weights have strong subjectivity and were unable to reflect the mechanical influences of weights on land-use change. Therefore, more scientific quantitative methods such as decision trees should be considered to determine the optimal weight threshold. Alternatively, spatial heterogeneity tools such as "Geodetector" may be used to detect the driving factors that cause the spatial heterogeneity of land-use change, and thus provide a better approach for cellular space partitioning.

The second concerns the possibility of more suitable attributes for evaluating the similarity of land-use change and its results. Although AWFLUC is an essential attribute for evaluating land-use change, it is limited by the temporal resolution of the original land use, and as such its impact mechanism on land-use change is still unclear. 
Author Contributions: Quanli Xu performed the research, put forward the idea, designed the CA models, and wrote the paper. Hong Liang gave an expert-level help in English writing. Jing Liu participated in the programming of CA simulation systems. Qing Wang dealt with testing data and prepared the testing documents. All authors have read and agreed to the published version of the manuscript.

Funding: This research was funded by "Agent-based modeling and simulation of imperviousness expansion during Dianchi Lake Basin urbanization based on ant behavior rules" grant number 41461038, "The multi-scale scene classification based on geographic landscape hierarchical model and regional statistical-modeling for high spatial resolution remote sensing images" grant number 41661082, and "High resolution remote sensing image intelligent understanding deep learning brain memory mechanism image segmentation" grant number 41861048. And the APC was funded by 41461038 .

Acknowledgments: We would like to thank the anonymous reviewers for contributing to improve this manuscript, as well as the editors for their kind work and professional support.

Conflicts of Interest: The authors declare no conflict of interest.

\section{Explanation of Abbreviation}

$\begin{array}{ll}\text { LUCC } & \text { Land-use and Land Cover Change } \\ \text { CA } & \text { Cellular Automata } \\ \text { LR } & \text { Logistic Regression } \\ \text { MC } & \text { Markov Chain } \\ \text { AI } & \text { Artificial Intelligence } \\ \text { SVM } & \text { Support Vector Machine } \\ \text { ACO } & \text { Ant Colony Algorithm } \\ \text { GA } & \text { Genetic Algorithm } \\ \text { NN } & \text { Neural Network } \\ \text { ANN } & \text { Artificial Neural Network } \\ \text { FLUC } & \text { The Frequency of Land-use Change } \\ \text { AWFLUC } & \text { The Area-Weighted Frequency of Land-use Changes } \\ \text { GDP } & \text { Gross Domestic Product } \\ \text { Model I } & \text { Non-partitioned CA model } \\ \text { Model II } & \text { Ordinary partitioned CA model (without considering AWFLUC) } \\ \text { Model III } & \text { AWFLUC-constrained partitioned CA model } \\ \text { Area 1 } & \text { Low-frequency area of land-use change } \\ \text { Area 2 } & \text { Medium-frequency area of land-use change } \\ \text { Area 3 } & \text { High-frequency area of land-use change } \\ \text { OA } & \text { Overall Accuracy } \\ \text { K } & \text { Kappa coefficient } \\ \text { AAUD } & \text { Analysis of accuracy ups and downs } \\ \end{array}$

\section{References}

1. Meyer, W.B.; Turner, B.L., II. Human population growth and global land-use/land-cover change. Annu. Rev. Ecol. Syst. 1992, 23, 39-61. [CrossRef]

2. Verburg, P.H.; Schot, P.P.; Dijst, M.J.; Veldkamp, A. Land use change modelling: Current practice and research priorities. Geojournal 2004, 61, 309-324. [CrossRef]

3. Paegelow, M.; Olmedo, M.T.C.; Mas, J.-F.; Houet, T.; Pontius, R.G., Jr. Land change modelling: Moving beyond projections. Int. J. Geogr. Inf. Sci. 2013, 27, 1691-1695. [CrossRef]

4. Li, X.; Liu, X. Case-based Cellular Automaton for Simulating Urban Development in a Large Complex Region. Acta Geogr. Sin. 2007, 62, 1097-1109. (In Chinese with English Abstract)

5. Wu, D.; Wang, R.; Gao, S.; Ding, W.; Wang, W.; Ge, X.; Liu, J. Simulation and scenario analysis of arable land dynamics in Yellow River Delta. Trans. CSAE 2010, 26, 285-290. (In Chinese with English Abstract) [CrossRef]

6. Liu, X.; Liang, X.; Li, X.; Xu, X.; Pei, F.; Ou, J.; Chen, Y.; Li, S.; Wang, S. A future land use simulation model (FLUS) for simulating multiple land use scenarios by coupling human and natural effects. Landsc. Urban Plan. 2017, 168, 94-116. [CrossRef]

7. Zhou, C.; Ou, Y.; Ma, T.; QIN, B. Theoretical Perspectives of CA-based Geographical System Modeling. Prog. Geogr. 2009, 28, 833-838. (In Chinese with English Abstract) 
8. White, R.; Engelen, G. Cellular Automata and Fractal Urban Form: A Cellular Modelling Approach to the Evolution of Urban Land-Use Patterns. Environ. Plan. A Econ. Space 1993, 25, 1175-1199. [CrossRef]

9. Mustafa, A.; Rienow, A.; Saadi, I.; Cools, M.; Teller, J. Comparing support vector machines with logistic regression for calibrating cellular automata land use change models. Eur. J. Remote. Sens. 2018, 51, 391-401. [CrossRef]

10. Lopez, S. Modeling Agricultural Change through Logistic Regression and Cellular Automata: A Case Study on Shifting Cultivation. J. Geogr. Inf. Syst. 2014, 6, 220-235. [CrossRef]

11. Mitsova, D.; Shuster, W.; Wang, X. A cellular automata model of land cover change to integrate urban growth with open space conservation. Landsc. Urban Plan. 2011, 99, 141-153. [CrossRef]

12. Lavalle, M.C. Modelling dynamic spatial processes: Simulation of urban future scenarios through cellular automata. Landsc. Urban Plan. 2003, 64, 145-160.

13. Rienow, A.; Goetzke, R. Supporting SLEUTH - Enhancing a cellular automaton with support vector machines for urban growth modeling. Comput. Environ. Urban Syst. 2015, 49, 66-81. [CrossRef]

14. Rienow, A.; Stenger, D.; Menz, G. Sprawling cities and shrinking regions - forecasting urban growth in the Ruhr for 2025 by coupling cells and agents. Erdkunde 2014, 68, 85-107. [CrossRef]

15. Li, X.; Lao, C.; Liu, X.; Chen, Y. Coupling urban cellular automata with ant colony optimization for zoning protected natural areas under a changing landscape. Int. J. Geogr. Inf. Sci. 2011, 25, 575-593. [CrossRef]

16. QuanLi, X.; Kun, Y.; Guilin, W.; Yulian, Y. Agent-based modeling and simulations of land-use and land-cover change according to ant colony optimization: A case study of the Erhai Lake Basin, China. Nat. Hazards 2014, 75, 95-118. [CrossRef]

17. Shafizadeh-Moghadam, H.; Tayyebi, A.; Ahmadlou, M.; Delavar, M.R.; Hasanlou, M. Integration of genetic algorithm and multiple kernel support vector regression for modeling urban growth. Comput. Environ. Urban Syst. 2017, 65, 28-40. [CrossRef]

18. Tayyebi, A.; Pijanowski, B.C. Modeling multiple land use changes using ANN, CART and MARS: Comparing tradeoffs in goodness of fit and explanatory power of data mining tools. Int. J. Appl. Earth Obs. Geoinf. 2014, 28, 102-116. [CrossRef]

19. Omrani, H.; Tayyebi, A.; Pijanowski, B. Integrating the Multi-Label Land Use Concept and Cellular Automata with the ANNbased Land Transformation Model. GISci. Remote Sens. 2017, 54, 283-304. [CrossRef]

20. Shafizadeh-Moghadam, H.; Asghari, A.; Tayyebi, A.; Taleai, M. Coupling machine learning, tree-based and statistical models with cellular automata to simulate urban growth. Comput. Environ. Urban Syst. 2017, 64, 297-308. [CrossRef]

21. Yeh, G.O.; Li, X. Simulation of Development Alternatives Using Neural Networks, Cellular Automata, and GIS for Urban Planning. Photogramm. Eng. Remote Sens. 2003, 69, 1043-1052. [CrossRef]

22. Aschenwald, J.; Fink, S.; Tappeiner, G. Brave new modeling: Cellular automata and artificial neural networks for mastering complexity in economics. Complexity 2010, 7, 39-47. [CrossRef]

23. Li, X.; Yeh, G.O. Neural-network-based cellular automata for simulating multiple land use changes using GIS. Int. J. Geogr. Inf. Syst. 2002, 16, 323-343. [CrossRef]

24. Li, X.; Yeh, A. Cellular automata for simulating complex landuse systems using neural networks. Geogr. Res. 2005, 24, 19-27. (In Chinese with English Abstract)

25. Jantz, C.A.; Goetz, S.J. Analysis of scale dependencies in an urban land-use-change model. Int. J. Geogr. Inf. Sci. 2005, 19, $217-241$. [CrossRef]

26. Şalap-Ayça, S.; Jankowski, P.; Clarke, K.C.; Kyriakidis, P.C.; Nara, A. A meta-modeling approach for spatio-temporal uncertainty and sensitivity analysis: An application for a cellular automata-based Urban growth and land-use change model. Int. J. Geogr. Inf. Sci. 2017, 32, 637-662. [CrossRef]

27. Kim, J.H. Spatiotemporal scale dependency and other sensitivities in dynamic land-use change simulations. Int. J. Geogr. Inf. Sci. 2013, 27, 1782-1803. [CrossRef]

28. Wang, J.; Xu, C. Geodetector: Principle and prospective. Acta Geogr. Sin. 2017, 72, 116-134. (In Chinese with English Abstract) [CrossRef]

29. Ke, X.; Bian, F. A Partitioned \& Asynchronous CA Based on Spatial Data Mining. J. Image Graph. 2010, 15, 921-930. (In Chinese with English Abstract)

30. Ke, X.; Deng, X.; Liu, C. Interregional Farmland Layout Optimization Model Based on the Partition Asynchronous Cellular Automata: A Case Study of the Wuhan City Circle. Prog. Geogr. 2010, 29, 1442-1450. (In Chinese with English Abstract)

31. Yang, Q. Dynamic Transition Rules for Geographical Cellular Automata. Acta Sci. Nat. Univ. Sunyatseni 2008, 47, 122-127. (In Chinese with English Abstract)

32. Ke, X.; Qi, L.; Zeng, C. A partitioned and asynchronous cellular automata model for urban growth simulation. Int. J. Geogr. Inf. Sci. 2015, 30, 637-659. [CrossRef]

33. Zhu, H.; Li, X. Discussion on the Index Method of Regional Land Use Change. Acta Geogr. Sin. 2003, 58, 643-650. [CrossRef]

34. Jain, A.K. Data clustering: 50 years beyond K-means. Pattern Recognit. Lett. 2010, 31, 651-666. [CrossRef]

35. Jiao, L.; Liu, Y.; Ren, Z. Spatial Points Clustering Based on Self-organizing Neural Networks and Its Application. Geomat. Inf. Sci. Wuhan Univ. 2008, 33, 168-171. (In Chinese with English Abstract)

36. Yang, J.; Shi, F.; Sun, Y.; Zhu, J. A Cellular Automata Model Constrained by Spatiotemporal Heterogeneity of the Urban Development Strategy for Simulating Land-use Change: A Case Study in Nanjing City, China. Sustainability $2019,11,4012$. [CrossRef] 